\title{
Petroleum Bottling Model in the Arctic Zone of Krasnoyarsk Region by Neural Network Forecasting
}

\author{
Aleksander Moskalev ${ }^{1 *}$, Yaroslav Grebnev ${ }^{1}$ \\ ${ }^{1}$ Siberian Federal University, pr.Svobodny 79\10, Krasnoyarsk, 660041, Russia
}

\begin{abstract}
Industrial development and active development of resources in the territory of the fragile Arctic ecosystem requires proper control of technological processes at enterprises located in these areas. Analysis and subsequent modelling of oil and oil products spills are performed in order to elaborate preventive measures concerning emergencies, means and methods of their liquidation being constantly ready to ensure safety of people and territories, as well as to reduce damage and losses as much as possible in case of their occurrence. The methods of oil product spill area assessment used at present, especially in the Arctic zone, have a number of limitations. This article presents modelling of the process of oil products spill to calculate pollutants concentration distribution and prediction of pollution area up to the moment of its localization with the application of neural network methods. The empirical results were got with NeuroPro neural network simulator and the PHOENICS software product were chosen. The simulation results were correlated with the data obtained in the analysis of an accident caused by depressurization of an aircraft fuel transfer pipeline from on an oil-loading pier on a river in the Arctic zone of Krasnoyarsk Krai.
\end{abstract}

\section{Introduction}

The Arctic zone is a unique and fragile ecosystem and habitat of many rare species of flora and fauna. Moreover, it is also an area which is rich in natural resources, with extensive exploration and industrial extraction of resources, which in turn increases the technogenic load on the ecosystem and the risks of emergencies. One of the most dangerous and widespread pollutants for the northern ecosystem is oil products used for heating and operation of transport and industrial machinery. Despite all the measures taken in the field of industrial safety, industrial accidents continue to occur, and their consequences cause significant harm to the environment and human health.

The analysis of accidents at oil storage facilities allows us to point out some general and special regularities of their occurrence. All accidents at oil storage facilities can be divided into the following groups depending on the cause of their origin:

a) depressurization of technological equipment ( $50 \%$ of cases);

b) human errors $(45 \%$ of cases $)$;

* Corresponding author: ak_moskalev@mail.ru 
c) external natural and man-caused factors ( $5 \%$ of cases).

According to our analysis of accidents their main causes are (Figure 1):

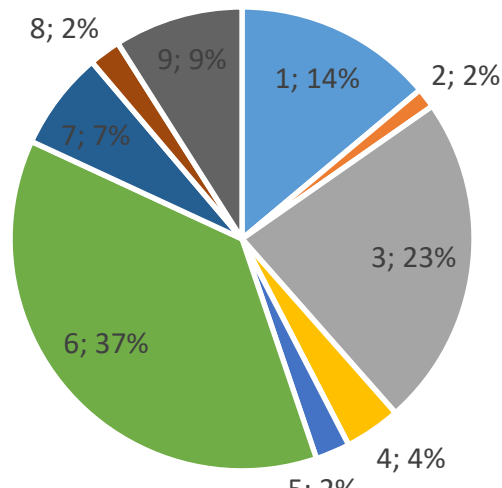

$5 ; 2 \%$

Fig. 1. Causes of accidents at fuel and oil storage facilities

( 1 - pipe defects, 2 - equipment defects, 3 - marriage of construction and installation works, 4 -violation of the rules of technical operation, 5 - internal erosion and corrosion, 6 - underground corrosion, 7 mechanical damage, 8 - natural disasters, 9 - others)

The problems of regulating the use of contaminated land and water bodies have been covered in the works of the following authors [1-3]. The issues of regulating the rational use of natural resources and ecology have been discussed in the works of the authors [4-5]. However, in general, the task of assessing the risks of emergencies in the northern territories is far from being completed. Emerging problems pose new challenges for researchers of the Arctic zone.

For example, the accident that occurred as a result of depressurization of the pipeline while pumping aviation fuel from a barge on one of the rivers of the Taimyrsky Dolgano-Nenetsky District in the Arctic zone of the Krasnoyarsk Krai set specific tasks for accident elimination. According to the Rosprirodnadzor's estimates (Rosprirodnadzor stands for the Federal Service for Supervision of Natural Resources) the damage caused to environment amounted to over $300 \mathrm{mln}$. rubles, yet, it is quite difficult to evaluate the consequences of such accidents completely, as elimination of consequences of accidental spills is quite a long-term undertaking and takes from several days up to several years depending on the volume of spilled oil products. It should be noted that this process also necessitates application of technologies for reclamation and ecological rehabilitation.

In this connection, the relevance of using modern methods of forecasting and mathematical modelling of the process of technogenic liquid spreading in permafrost zones is beyond doubt. The neural network modelling method, which makes it possible to identify regularities and build dependencies on the basis of a large amount of data. Besides, this method allows for timely modelling of natural and technogenic processes and phenomena. The main difficulty in applying neural network forecasting is the qualitative preparation of archive data. It is worth mentioning that at present the analysis of the causes of hazardous events is widely used in assessing the risk of man-made emergencies coupled with statistical methods of processing data of operational monitoring and observation archives and building prediction models on their basis [6-8].

In this work, we set a goal of developing a model for predicting oil spills by neural network forecasting. The results of modelling will be correlated with the data obtained during the analysis of the consequences of the accident described earlier. 


\section{Materials and Methods}

In this article, we reduced the calculation of oil product concentration in a water body to the solution of Reynolds equations for turbulent flow, taking into account energy and pollutant concentration equations.

To solve the task, there were used software products PHOENICS [10] and NeuroPro 0.25 developed at the Institute of Computational Modelling of the KSC SB RAS [11].

To solve the problem of modeling of oil falling into the Yenisei River, used multilayer neural network with sigmoid activation functions, neural network learning algorithm and parameters for the simulation are presented in [12]

The input parameters were selected empirically. To train the neural network, we created a normalized array with parameters containing data on an oil spill that occurred near the settlement of Tukhard. The data were derived from the databases of from the Main Directorate of Ministry of Emergency Situations of Russia in Krasnoyarsk Krai, the Agency for Civil Defense, Emergencies and Fire Safety of Krasnoyarsk Krai.

The dimensionality of the vectors of parameters noted above was calculated empirically and was equal to seventeen. In the calculation we used a multilayer neural network with 12 layers and the number of neurons in the hidden layer equal to 204. This model showed good results in practice. The percentage of reliability of the results obtained fell in the range of 60$72 \%$.

\section{Results and discussion}

The upper right corner of Figure 3 (the area map) displays a generalised model of the situation following an accidental oil spill.

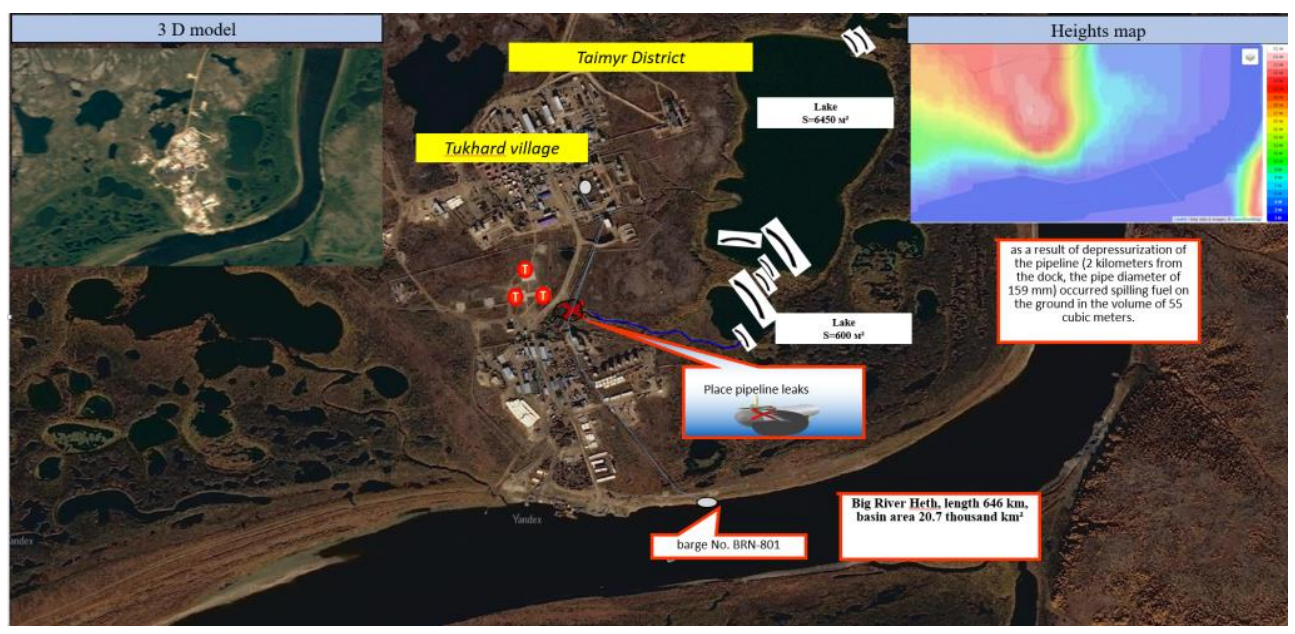

Fig. 2. Image of a generalised spreading model (right corner of figure), combined with a map of the oil products rupture

The problem of determining oil products spread in the river was solved by numerical methods. The results of the solutions were verified by reducing the size of the control volumes. Visualisation of modelling results were presented as two-dimensional images along the $x_{1} x_{3}$ or $x_{1} x_{2}$ axes.

Figure 4 shows the distribution of oil products concentrations in the Bolshaya Kheta River. The highest values of $C_{l}$ concentration $=0.959 ; 0.919 ; 0.858$ were obtained in the immediate vicinity of the place of ingress of oil products into the water body, which is shown in the figure in red. Depending on the time of ingress and transfer of oil products in the river, the oil slick emulsifies with water and 
spreads with the current, which decreases the oil product concentration accordingly. Oil products concentrations vary from $C_{l}=0.2$ to 0.8 ; this is shown in the figure by colours changing from yellow to blue.

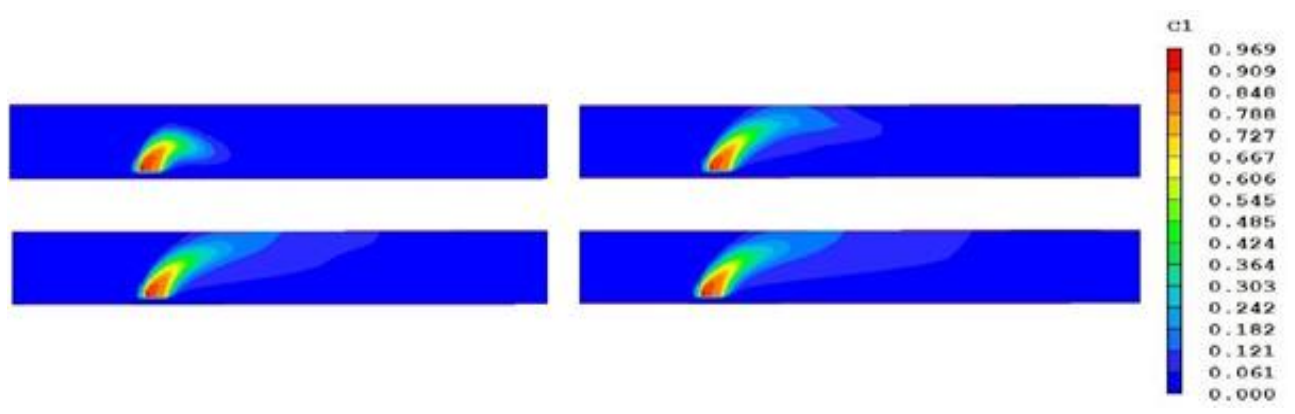

Fig. 3. Distribution of $C_{l}$ concentration in different time periods (side view along the axis $x_{1} x_{3}$ )

The top view of the water surface is shown in Figure 5. Depending on the spread of the oil slick in the water surface, the oil slick took on a horseshoe shape, as the flow of oil products due to its high density inhibits the river flow.
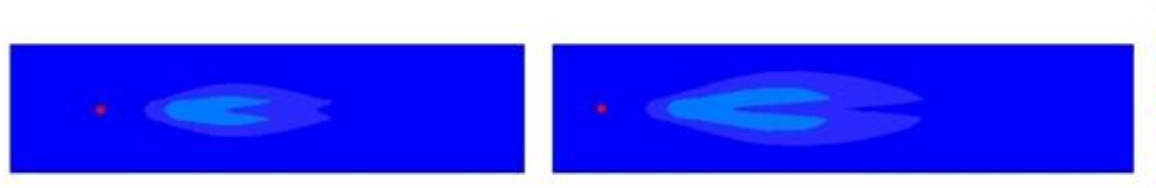

c1
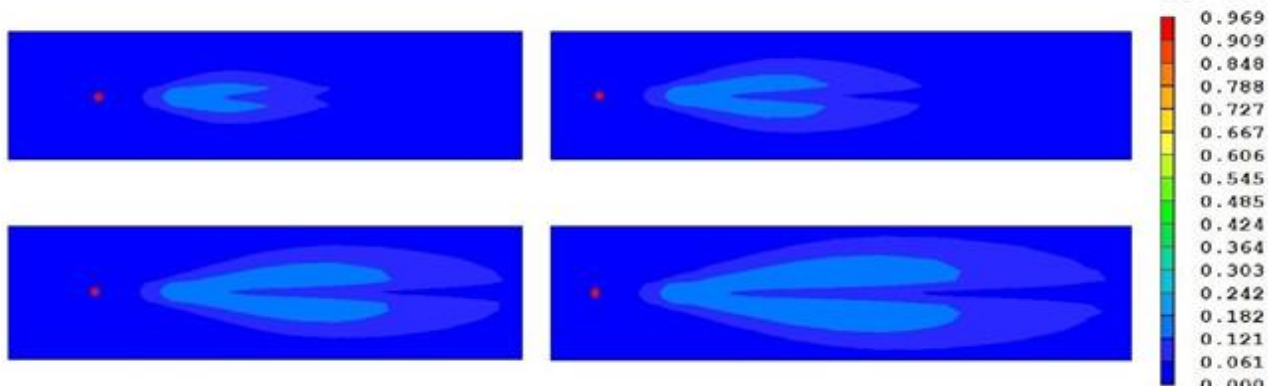

Fig. 4. Distribution of $C_{l}$ oil flow concentration on water surface at different points in time (top view on axes $\left.x_{1} x_{2}\right)$.

The amount of oil which leaked in 10 minutes while personnel were not responding to the emergency:

$$
m=C_{1} \cdot w \cdot S \cdot t
$$

where $\mathrm{m}$ - amount of oil products, $\mathrm{kg} ; C_{l}$ - oil products concentration; $w$ - velocity of oil products outflow; $S$ - crack area; $t$ - time of outflow.

For the parameters of a particular accident, the amount of oil m1 was $38471.7 \mathrm{~kg}$.

The oil emulsions would subsequently be carried by the river current for a considerable distance. According to these calculations the oil slicks, emulsified with water, would be carried by the current for $40 \mathrm{~km}$ from the spill area.

It is important to mention that the modelled situation implies continuous flow of oil products into the water body; however, in real situation oil products flow out of the reservoir as a result of depressurization in portions and, accordingly, enter the water body in the same way. There are small discrepancies between this model and the reality. Carrying out additional experiments in this area is of great interest and at the same time not a trivial task.

The second task, namely neural network prediction of the oil slick area, was done using the methodology described earlier in the Materials and methods section. Using data of daily monitoring of oil products spread, data on pollution area and other parameters described above, we trained the neural network and modelled the development of the situation. The 
obtained computational results were compared with the real results obtained from monitoring of the situation in the area of the emergency.

A comparison of the results obtained using the neural network and the real values of the oil slick area is presented in Table 1.

Table 1. Data on actual and estimated oil slick area.

\begin{tabular}{|c|c|c|c|}
\hline Date & $\begin{array}{l}\text { Actual cumulative } \\
\text { area, } \mathbf{m}^{2}\end{array}$ & $\begin{array}{c}\text { Estimated cumulative } \\
{\text { area, } \mathbf{m}^{2}}^{2}\end{array}$ & Deviation \\
\hline 12.07 .2020 & 15200 & 14800 & 400 \\
\hline 13.07.2020 & 22600 & 21200 & 1400 \\
\hline 14.07.2020 & 29300 & 33350 & -4050 \\
\hline 15.07 .2020 & 32200 & 35100 & -2900 \\
\hline 16.07.2020 & 35500 & 36100 & -1100 \\
\hline 17.07.2020 & 36800 & 36500 & 300 \\
\hline 18.07.2020 & 38300 & 38500 & 200 \\
\hline
\end{tabular}

Oil products spread slowly at the water surface, but quickly become waterlogged, losing buoyancy, and their density becomes close to $1 \mathrm{~g} / \mathrm{cm} 3$. Predicting the quantification of waterlogged oil product is quite challenging as it is highly dependent on local conditions (water temperature, amount of suspended solids in the water and so on). Taking into account turbidity of river water, presence of large amount of suspended solids, one should expect partial flooding of spilled oil product within several hours after the spill. There is no sufficiently rapid biodegradation of oil products. Therefore, the urgency of measures to collect spilled oil products within the first hours after the spill becomes apparent. After the accident, oil product was freely spilled on the water surface downstream for 6 hours towards the stationary booms installed after the accidental spill, which resulted in contamination of the water surface up to the booms. The estimated area of the spill on the water was 38.300 $\mathrm{m} 2$. The use of booms is reflected in the results obtained by neural network modelling (in Table 1 starting from 14.07.2020), as factual prediction of the timing and amount of booms and sorbent agents is a separate, complex task that is quite difficult to estimate numerically. Indeed, when the oil products were accumulated near the booms, the spill area decreased and there was also partial contamination of the shoreline. The average thickness of the spilled oil product layer was $0.003 \mathrm{~m}$.

The emergency response technologies must take into consideration approximate quantity and basic properties of oil products; peculiarities of territories (relief, soils, vegetation); characteristics of oil products and conditions of their spread; impact of hydrometeorological conditions; safety measures during emergency operations of oil products spill response; characteristics of technical means for oil products spill containment and containment methods; characteristics of technical means for collection of oil products, oil-contaminated waste, soil, methods of cleaning territories; specifics of oil products spill elimination in winter; specifics of oil products spill elimination by sorbent materials and chemical agents.

\section{Conclusion}

Due to the deterioration of equipment and insufficient control, the most probable and dangerous emergency situations in the territory of the Arctic zone of the Krasnoyarsk Krai enlist oil products spill during oil tanker accidents or oil spill on any vessel, depressurization of the main oil pipeline due to mechanical damage or corrosion, depressurization of the oil pipeline fuel tanks as a result of mechanical damage or corrosion.

In this article we tested a method of modelling and neural network prediction of a real emergency situation arising as a result of depressurization of the pipeline during oil fuel 
pumping from a barge on an oil pier in a settlement in the Arctic zone of the Krasnoyarsk Krai. The calculated distribution of fuel flow concentration on the water surface at various points in time allowed for the correct positioning of downstream booms. This man-made action was reflected in the predicted results based on neural network modelling of the emergency situation as a discrepancy with the actual data. Subsequently, when updated information came in, the situation forecasting results were restored. The peculiarity of liquidation of consequences of accidents in the North with its longer terms and high expenditure demand different methods of digitalization and in this respect the use of neural network modelling is supposed to be reasonable. The obtained results can be applied in the development of plans for prevention and elimination of emergency oil and oil products spills.

The reported study was funded by RFBR according to the research project No. 20-37-90090.

\section{References}

1. V. Moskvichev, I. Bychkov, V. Potapov, Taseiko O, Shokin Y, 2017 Information system of territorial development and security risk management Bulletin of RAS 87(8) 696-705

2. O. Medvedeva and S. Solovieva 2016 Methodology for the valuation of damage caused by atmospheric air pollution Issues of valuation 4 (86) 2-6

3. X. Li, G. Chen, H. Zhu, 2007 Modelling and assessment of accidental oil release from damaged subsea pipelines Marine Pollution Bulletin. Vol. 123 133-141.

4. Ya. Grebnev, A. Moskalev, 2020 Influence of hydroelectric power station on flood situation and modelling of hydrological characteristics. E3S Web Conf. Volume 221, 17

5. R. Guandalini, G. Agate, Moia F. 2017 Numerical 3D modelling of oil dispersion in the sea due to different accident scenarios Energy ProcediaVol. 125 161-169.

6. Ya. Grebnev, A. Moskalev, A. Vershkov, A. Gazizulina, The practice of connectionist model for predicting forest fires in the Arctic zones of the Krasnoyarsk Territory. International Journal of System Assurance Engineering and Management Int J Syst Assur Eng Manag.. 2019. P.1-9.

7. Ya. Grebnev and A. Yarovoy, 2018 Monitoring and forecasting floods in the Krasnoyarsk Territory using neural network algorithms Scientific and analytical journal "Siberian Fire and Rescue Bulletin", Vol 3 13-16.

8. A. Fentiman and N. Zabbey, 2015 Environmental degradation and cultural erosion in Ogoniland: a case study of the oil spills in Bodo Extr Ind Soc Int J 2 615-624

9. S. V. Patankar, 1984 Numerical methods for solving problems of heat transfer and fluid dynamics. (Moskow) Energoatomizdat p 152

10. Official website of Phoenics software. URL: http://www.cham.co.uk/phoenics.php

11. A. Gorban, et al 1998 Neuroinformatics (Novosibirsk: Nauka, SB RAS) p 296

12. Y. Grebnev and A. Moskalev 2021 Modelling the accidental oil spills at potentially hazardous facilities in the Arctic zone of Krasnoyarsk Krai IOP Conference Series: Earth and Environmental Science. - Volume 816. - 2021. - P. 1-9. 